\title{
The Need of Laws to Reduce the Impact of Alcohol Marketing on Youth under 18 Years Old in Ethiopia
}

\author{
Workneh Alemnew Alula
}

School of Law, University of Gondar, Ethiopia

Copyright $\subseteq 2017$ by authors, all rights reserved. Authors agree that this article remains permanently open access under the terms of the Creative Commons Attribution License 4.0 International License

\begin{abstract}
The proportion of teenagers who drink alcoholic beverages regularly is increasing and many young people start drinking from a very young age in Ethiopia. There are compelling evidences about the negative impact of drinking by young people not only on their health, but it is also known to be a major contributory factor for much of the crime and anti-social behavior carried out by young people. So, reducing the impact of alcohol marketing on young people is not only a public health goal but also a public law goal since underage drinking is a significant contributor to youth alcohol-related crimes, suicide and problems associated with school and family. Young people drink earlier more often and more frequently when exposed to alcohol marketing. There is known to be a link between alcoholic beverages advertising and people's alcohol consumption, particularly those under the age of 18 . This study argues that any advertisement of liquor shall not concentrate on minors or use a minor as an advertisement actor so as to protect minors from negative impacts of alcohol consumption. Besides the large volume of alcohol advertising practices encountered in Ethiopia, the content of the advertisements stand out and are part of a very aggressive marketing strategy which might be interpreted as unethical. Moreover, there is no law that prescribes liability against alcohol manufacturers and sellers which serve alcohol to a boy or a girl under 18 years old in Ethiopia. Regarding methodology, this study uses qualitative data by assessing the laws and policies of the country Vis-à-vis international experiences. It, therefore, focuses on the following research questions: (1) do alcoholic beverages manufacturing companies transmit ethical and legal advertisements in accordance with the Ethiopian Advertisement Proclamation No.759/2012? (2) do advertisements of alcoholic beverages concentrate on minors? (3) is there a need of laws that prescribe liability against alcohol manufacturers and sellers which serve alcohol to a youngster who is under 18 years old?; and finally is there a need of vibrant laws to reduce the impact of alcohol marketing on youth? This study recommends that there should be regulatory legal frameworks on underage alcohol drinking in Ethiopia. Hence,
\end{abstract}

the alcohol marketing regulatory framework should be stringent and established by law in Ethiopia.

Keywords Alcoholic Beverages, Young People, Advertisement, Regulation

\section{Introduction}

\subsection{Background of the Study}

There is growing public concern about how much alcohol young people are drinking in their teenage years. ${ }^{1}$ The proportion of teenagers who drink regularly is increasing and many young people start drinking from a very young age. ${ }^{2}$ Young people who drink too much put their own health at risk. ${ }^{3}$ They are also more likely to get involved in anti-social behavior and contribute to insecurity on streets. Hence, the

${ }^{1}$ See Richmond Surrey (2008), Youth Alcohol Action Plan, The Secretary of State for Children, Schools and Families, the Secretary of State for the Home Office and Secretary of State for Department of Health of United Kingdom, p.2.

${ }^{2}$ Global Actions (2013), Commitments to reduce harmful drinking, Regulatory framework to prevent underage drinking, a review, p. 3, accessed at www.globalactions.com, last visited on August 1, 2014.

${ }^{3}$ See Supra note 1 . Drinking at an early age can cause serious health problems, both in the short and the long-term. There is also new evidence that drinking too much alcohol can impair adolescent brain development. Drinking too much alcohol is strongly associated with a wide range of other problems which adversely affect the welfare of teenagers, for example, unprotected sex, teenage pregnancy, failing at school and theuse of illicit drugs. Based on medical and other evidence, the Australian Government recently concluded that there is no amount of alcohol that can be said to be safe and that young people under the age of 18 should not drink to become intoxicated. There is disturbing evidence from the UK of: a sharp increase in liver cirrhosis among people in their $20 \mathrm{~s}$ - almost certainly linked to heavy alcohol consumption in the teenage years; a strong association between alcohol consumption and accidents involving young people. This is particularly the case for road traffic accidents - but also related to accidents and injuries more generally. Thirteen children a day are admitted to hospital as a result of drinking alcohol; and rising deaths among young people linked to alcohol - there has been a 57 per cent increase in alcohol-related deaths amongst young people aged 15-34 between 1991 and 2006.

${ }^{4}$ See Wilson D. Sharp C. and Patterson A. (2005): Young People and Crime: Findings from the 2005 Offending, Crime and Justice Survey London: Home Office Statistical Bulletin 17/06. In addition to individual health 
prevention of alcohol drinking by young people is one of the key areas of emphasis for governments, public health professionals, communities, families and also the alcohol beverage industry. 5

As a point of departure, governments of many countries have developed a regulatory framework to address youth drinking through legislations governing the age thresholds at which young people are legally permitted to purchase and consume alcohol beverages. ${ }^{6}$ This regulatory framework provides an important backdrop for prevention activities to prevent drinking by young people with particular emphasis on individuals below the legally mandated age limits. ${ }^{7}$ Most existing legal age limits pertaining to alcohol converge on 18 years of age which is also the most common standard age of legal majority. However, some countries set threshold ages for alcohol as low as 15 or as high as 25 years of age. ${ }^{8}$ Legal age thresholds for the purchase and consumption of alcohol beverages are usually set by governments at the national level but in some cases may be defined at the sub-national or state level. ${ }^{9}$ The policies of developed countries to date have focused heavily on stronger enforcement of laws on sales of alcohol to young people and on tackling alcohol-related disorder and crime. ${ }^{10}$ Nevertheless, it is clear that more needs to be done. Therefore, enforcement efforts need to be complemented with further powers and actions that take into account the changes in young people's drinking habits and the public's concern. ${ }^{11}$

Many developing countries have also put into effect Alcohol Drinking Control Acts that have the purpose of controlling of the production, sale and use of alcoholic drinks in order to protect the health of young people in the light of the dangers of excessive consumption of alcoholic drinks. For instance, the Alcoholic Drinks Control Act No. 4 of 2010 of Kenya ${ }^{12}$ is intended to protect the health of persons under

harms, teenage consumption of alcohol is linked with wider and serious problems that impact on society more generally. In particular: alcohol consumption is one of the key factors associated with young people committing offences. Evidence suggests that 10-15-year-olds who have been drunk once a month or more in the past year were over twice more likely to commit an offence than those who had not. More specifically, drinking by young people is associated with violence.

${ }^{5}$ See Supra note 2 (Global action)

${ }^{6}$ See John Eckhart (2014), Oregon Liquor Control Commission, Oregon's Alcohol Laws and Minors, pp.1-2, accessed at www.oregon.gov/OLCC last visited on July 20, 2014.

${ }^{7}$ See supra note 2 . Underage drinking review, page 1

8 Ibid

${ }^{9}$ See Ibid and U.S. Department of Justice (2009), Enforcing Underage Drinking Laws Program, Office of Juvenile Justice and Delinquency Prevention, p. 4, accessed at www.ojp.usdoj.gov, last visited on July 24, 2014. For example, in the United States, a purchase age of 21 applies universally, but is legislated at state level. Underage drinking is widespread in the United States. Approximately 12.5 million underage youth drink each year. Similarly, age limits in Canada are mandated by provincial governments, some of which set them at 18 and others at 19 years of age. In Switzerland, cantons have the discretion of setting their own on- and off-premise thresholds, defined as either 18 or 19 years of age. In India, alcohol policies, including age thresholds, are set by individual states. Where alcohol consumption and purchase are permitted, age limits vary between 18, 21, and 25 years of age.

${ }_{10}$ See Supra note 1, Richmond Surrey (2008), Youth Alcohol Action Plan. ${ }^{11}$ Ibid

${ }_{12}$ See the Alcoholic Drinks Control Act No. 4 of 2010 of Kenya, Revised Edition 2012, published by the National Council for Law Reporting with the Authority of the Attorney-General, p.9, accessed at www.kenyalaw.org, last the age of eighteen years by preventing their access to alcoholic drinks. In general, it is intended to tackle the negative impact of alcohol consumption by youth.

Alcohol marketing research findings from Gambia, Ghana, Nigeria and Uganda shows that the greater the exposure, the greater the impact. ${ }^{13}$ As per the research findings, young people drink earlier more often and more frequently when exposed to alcohol marketing. This effect is larger when being exposed to larger volumes of alcohol marketing and when the content of the advertisement is appealing to young people. ${ }^{14}$ Although, there is no impact research performed in African countries in general, it can be expected that the effect of exposure to alcohol marketing is even stronger in relatively new markets where ideas on alcohol are still developing. ${ }^{15}$

When considering the greater exposure to alcohol marketing, the greater the impact; a great worry arises when looking at the African countries studied. ${ }^{16}$ Except few African countries like Gambia, alcohol producers have a lot of freedom in alcohol marketing activities due to a limited or absent alcohol marketing policy in most of the African countries ${ }^{17}$ The size, frequency and placement of alcohol advertisements and sponsorship of alcohol marketing in Ghana, Nigeria and Uganda are aimed at reaching large audiences. ${ }^{18}$ Many adults aswell as minors are exposed to alcohol marketing because of broadcasting alcohol advertising in the main media and on the streets. ${ }^{19}$ They can be easily reached by multiple channels, such as, by a combination of marketing in the broadcasting media, by sponsoring cultural and sportive events and other types of marketing. ${ }^{20}$ The same is true in Ethiopia. One of the major alcohol marketing regulatory frameworks is alcohol advertisement regulation. ${ }^{21}$ There is known to be a link between advertising and people's alcohol consumption, particularly those under the age of $18 .^{22}$ These facts call for the need of regulation of underage alcohol drinking in Ethiopia.

\subsection{Objectives of the Study}

visited on July 20, 2014.

${ }^{13}$ By Avalon De Bruijn (2011), Alcohol Marketing Practices in Africa, Findings from the Gambia, Ghana, Nigeria and Uganda, Dutch Institute for Alcohol Policy (Stap) Utrecht, the Netherlands, p. 68.

${ }^{14}$ Ibid

15 Ibid

${ }^{16}$ Alaniz, M.L., \& Wilkes, C. (1998) Pro-drinking messages and message environments for young adults: The case of alcohol industry advertising in African American, Latino, and Native American communities. Journal of Public Health Policy, Vol.19 No. 4, pp. 447-471.

17 Ibid

18 Ibid

19 The Secretary of State for the Home Department (2012), The Government's Alcohol Strategy, Printed in the United Kingdom by The Stationery Office Limited on behalf of the Controller of Her Majesty's Stationery Office, pp.6-7.

20 Ibid

21 Ibid

22 See Booth, A., Meier, P., Stockwell, T., Sutton, A., Wilkinson, A., Wong,

$\mathrm{R}$. (2008) Independent review of the effects of alcohol pricing and promotion.United Kingdom, Department of Health, p.7. 


\subsubsection{General Objectives of the Study}

The general objective of this study principally is to deal with the need of laws to reduce the impact ofalcohol marketing on youth in Ethiopia. The study, accordingly, aims at achieving two equally important objectives. First, it aims at contributing to knowledge about the need of laws to reduce the impact ofalcohol marketing on youth. Second, it, in light of the research background indicated above, aims at indicating the need, areas and nature of further action by the country in general and the Brewery Companies and sellers of alcoholic beverages in particular to protect the youth under 18 years old from harmful alcohol consumption by consulting best practices in the enforcement of legal age limits for selling and serving alcoholic beverages.

\subsubsection{Specific Objectives of the Research}

This research;

- provides relevant and research based information for law makers, alcoholic beverages manufacturing companies, alcoholic beverages retailers and sellers, lawyers, youngsters under 18 years old, the general public and other stake holders for further action.

- $\quad$ serves as a reference to further researches.

- contributes knowledge to the existing discourse on the need of laws to reduce the impact ofalcohol marketing on youth in Ethiopia .

This paper focuses on the following research questions:

- Do alcoholic beverages manufacturing companies transmit ethical and legal advertisement in Ethiopia in accordance with FDRE Advertisement Proclamation No.759/2012?

- Do advertisements of alcoholic beverages concentrate on minors in Ethiopia?

- Is there a need of vibrant laws to reduce the impact of alcohol marketing on youth?

- Is there a need of laws that prescribe liability against alcohol manufacturers and sellers which serve alcohol to a boy or a girl who is under 18 years old?

\subsection{Methodology of the Study}

The study is fundamentally qualitative. It, however, uses some quantitative data to substantiate conclusions. The participants of this research were selected from "TikurAmbesa" Secondary School in Addis Ababa purposively since the school is located at the center of the city in which there are many hotels, bars and restaurants serving alcoholic beverages to the students. Addis Ababa was purposively selected for the reason that it is home for many institutions that can contribute to the objectives of this study. Adolescents (grade 10 students) have got the chance to be respondents in the survey. About a sample of 217, both males and females were involved in the study. The sample size determination was done based on Kepik-lab Solvin's sample size calculator. According to this sample size calculator, these numbers (217) of participants are assumed to be representatives of the total population (1347) with 95\% confidence level and 5\% error. Stratified random sampling technique was served as the basis for selecting samples from the target population. This sampling technique is important to select males and females equally based on their proportion In order to take participants proportionally based on the strata of sex, the following formula was used from the population of 1347 :

$$
\begin{gathered}
\mathrm{N}=1347 \\
\mathrm{~N} 1=851 \\
\mathrm{~N} 2=496 \\
n 1=\frac{N 1(n)}{N}=n 1=\frac{(851)(217)}{1347}=137 \\
n 2=\frac{N 2(n)}{N}=n 2=\frac{(496)(217)}{1347}=80 \\
\mathrm{n}=\mathrm{n} 1+\mathrm{n} 2=137+80=217
\end{gathered}
$$

Where;

$\mathrm{N}=$ total population

$\mathrm{N} 1=$ total population of females

$\mathrm{N} 2=$ Total population of male

$\mathrm{n}=$ total sample

$\mathrm{n} 1=$ sample of females

$\mathrm{n} 2=$ sample of males

There is no much wealth of literature in respect of enforcement of a legal age limit for the sale of alcohol in Ethiopia. Therefore, this theme of research is a virgin area for further research. This study takes advantage of the gaps and is conducted through the following:

- Use of data from interview questions as to underage alcohol drinking.

- Use of data from questioners as to underage alcohol drinking.

- Literature study and consultation of the laws and regulatory practices of countries as to their effort to establish a legal age limit for the sales of alcohol and to avoid illegal and unethical advertisements that concentrate on youngsters under eighteen years old;

- Comparison of the Ethiopian policies, laws and practices with best policies, laws and practices of developed legal systems

- Analysis of the existing Ethiopian policies and laws relating to the issues of the study.

- Use of data from official reports and unpublished records of the alcohol manufacturing companies, the regulators and related institutions in the country;

- Field study of the alcoholic beverages market practices in Ethiopia (through visits and discussions with appropriate personnel and individuals).

\section{The Current Ethiopian Situation on}




\section{Underage Alcohol Consumption}

To begin with the findings of this study, surprisingly, ninety percentages of the students responded that they drink alcohol when they have financial ability to buy alcoholic beverages. $89 \%$ of the students had at least one drink of alcohol on one or more days during their life. $60 \%$ had at least one drink of alcohol on one or more occasions in the past 30 days. $35 \%$ had five or more drinks of alcohol in a row (i.e., binge drinking) in the past 30 days.

When we see the determinant factors of underage consumption of alcohol, those students belonging to a relatively richer household tends to increase alcohol consumption. Peer effect is also the other factor for underage drinking. The probability of having drunk any alcohol in the past 30 days is more than $60 \%$ when an average student reports that most or all his/her friends drink. The peer effect is larger for girls than for boys. If most or all friends drink, the probability of having drunk beer in the past is on average $68 \%$ for males and $80 \%$ for females. Turning to the frequency of consumption in the past, students who respond that most or all their peers drink, are also more habitual consumers. This implies that underage alcohol drinking is widespread in Ethiopia.

When we see the current legal frame work of Ethiopia, Article 26 (4) of Advertisement Proclamation No.759/2012 of the Federal Democratic Republic of Ethiopia (hereinafter referred as FDRE) provides that "an outdoor advertisement of any liquor may not be placed within 100 meters radius of a children care center, school, medical or historical institution, cinema or theater hall or a stadium". However, the practice reveals a different scenario. For instance, when we see Addis Ababa stadium which is the best stadium in Ethiopia, most of brewery factories in the country have installed billboards promoting their alcoholic beverages within the compound of the stadium. It is a matter of common knowledge that most of the spectators in stadiums are the youth. We can also observe that the Dashen Beer billboards are placed within 100 meters radius of Fasilledes Castle, Cinema Gondar and High schools. As indicated above, young people drink earlier more often and more frequently when exposed to alcohol advertisements. This study argues that any advertisement of liquor shall not concentrate on minors or use a minor as an advertisement actor so as to protect minors from negative impacts of alcohol consumption. Therefore, the alcohol marketing regulatory framework should be stringent and established by law in Ethiopia.

Moreover, in Ethiopia, there is no law that prescribes liability against alcohol manufacturers and sellers which serve alcohol to a boy or a girl who is under 18 years old. In developed legal systems, such as the USA, alcoholic beverage sellers are held liable if they sell alcohol to someone under 18 years old. ${ }^{23}$ For instance, if a bar, hotel or

${ }^{23}$ Federal Trade Commission.(1999) Self-regulation in the alcohol industry: A Federal Trade Commission report to Congress. Washington, DC: Federal restaurant operator serves alcohol to a boy or girl who is under 18 years old, the operator would be civilly and criminally liable for the resulting injuries. ${ }^{24}$ However, most of the liquor manufacturers and sellers in Ethiopia target their market on the youth. The youth under 18 years old in Ethiopia are the targets of alcoholic beverages market and many bars, hotels or restaurants sell different kinds of alcoholic beverages to minor boys and girls without screening the age of customers. Because of this, most of Ethiopian alcohol manufacturing companies do not want to state in their advert that the youth under 18 years old shall be prohibited from alcohol drinking. ${ }^{25}$

Besides the large volume of alcohol advertising practices encountered in Ethiopia, the content of the adverts stand out and are part of a very aggressive marketing strategy which might be interpreted as unethical. For instance, when we see the advert of "Meta" beer in all types of Medias, the advert states that Meta Beer is a "Lion Beer". The advert of "Habesha" beer states that "Habesha" beer is a cold gold. Here, we may ask a query that: how could a Beer looks like a lion and a cold gold? In fact, most of the alcohol manufacturers have transmitted such kinds of unethical advertisements so as to attract the youth under 18 years old to drink alcohol and finally to maximize their profit. Hence, it is possible to argue that most of the Ethiopian alcohol manufacturers neglect their corporate social responsibility since they are not willing to protect the youth under the age of 18 years by preventing their access to alcoholic drinks.

As indicated above, there is compelling evidence about the negative impact of drinking by young people, not only on their own short- and long-term health, but it is also known to be a major contributory factor, and in some cases the sole motivation for much of the crime and anti-social behavior carried out by young people. Reducing the impact of alcohol marketing on young people is not only a public health goal but also a public law goal since underage drinking is a significant contributor to youth alcohol-related crimes, suicide and problems associated with school and family. ${ }^{26}$

Therefore, Ethiopia should have an Alcoholic Drinks Control Act (law) like South Africa and Kenya, for the purpose of protecting the youth under the age of eighteen years by preventing their access to alcoholic drinks. The law will be an important tool to avoid or minimize alcohol-related crimes to be committed by minors. The above mentioned facts call for the need of laws to reduce the impact ofalcohol marketing on youth in Ethiopia. In this

\footnotetext{
Trade Commission

${ }^{24}$ Ibid.

${ }^{25}$ The writer observes that only Meta brewery S.C has started "drink responsibly campaign" in Ethiopia. Meta Brewery S.C has promoted that the youth under 18 years old shall not be allowed to drink Meta beer. However, other Brewery Companies have no willingness to save the youth under 18 years old from the harms of alcohol drinking in Ethiopia. The writer believes that all Brewery Companies should apply the "drink responsibly and prohibition of underage alcohol drinking campaign".

See U.S. Surgeon General, (2007) surgeon general's call to action to prevent and reduce underage drinking. Washington, Dc: Department of Health and Human Services, office of the surgeon general.
} 
regard, the writer has communicated the top management members of Dashen Brewery S.C as to the need of regulation of underage alcohol drinking in Ethiopia. Mr.MulugetaMaru who is chief executive secretary of the board of Dashen Brewery S.C and Mr. ZewuduAmsalu who is the head of the legal department of Dashen Brewery S.C have expressed the interest of their company for the need of underage alcohol drinking regulation.

\section{Effect of Unethical Advertising on Adolescents Alcohol Consumption in Ethiopia}

There is known to be a link between alcoholic beverages advertising and people's alcohol consumption, particularly those under the age of 18. As indicated above, most of the alcohol manufacturers in Ethiopia have transmitted unethical advertisements so as to attract the youth under 18 years old to drink alcohol and finally to maximize their profit. Some participants of this study put forward solutions that could protect young people from the influence of alcohol advertising meant for adults. ${ }^{27}$ These related to timing of advertisements on the media and measures to review their contents; "for advertising for alcoholic drinks to have a separate channel on the media" and having guidelines to "censor alcohol advertisements before transmission to the public". In addition, "timing of advertisements should be revised and advertisements shall be transmitted after most children go to bed". "Medias shall also avoid alcohol advertising in and around programs in which young people are possible audiences". The other dimension that could help preclude young people's exposure to alcohol advertising is to avoid filming advertisements in locations frequented by young people especially by those below 18 years of age.

Concerning sponsorships, event organizers themselves should take the responsibility: It may be youth event organizers themselves who seek sponsorship money from alcohol companies. Hence, those involved in youth organizations should have clear standards regarding alcoholic drinks in relation to the importance of youth events. Alcohol manufacturers have responsibility to safeguard minors through responsible advertising of alcoholic drinks and exclude children and the youth from their advertising targets. The Ethiopia government should also take appropriate measures against Alcohol manufacturers which place an outdoor advertisement of any liquor within 100 meters radius of a children care center, school, medical or historical institution, cinema or theater hall or a stadium in violation of the Advertisement Proclamation No.759/2012.

\footnotetext{
${ }^{27}$ Interview with Mr. MulugetaMaru who is chief executive secretary of the board of Dashen Brewery S.C and Mr.ZewuduAmsalu who is the head of the legal department of Dashen Brewery S.C, 15 September, 2016
}

\section{Comparative Laws}

People who care about young people are aware of the serious problems caused by underage alcohol use. Laws and regulations have the potential to be particularly effective in reducing underage access to alcohol. Some countries have introduced a complete ban on alcohol advertising (Norway) or a ban on Television advertising with other controls (France) to tackle the negative impact of alcohol consumption by youth. ${ }^{28}$

South Africa's laws on underage drinking, in comparison to Ethiopia's, more explicitly delineate the unlawful aspects of underage drinking and its surrounding activities. Section 10 of the South African Liquor Act 59 of 2003 bars a person from selling or supplying liquor to a person under age 18 , but includes an exception which allows an under-18 year old to consume a moderate quantity of liquor in the presence of a parent, a guardian or a person responsible for administering a religious sacrament. The South African law also requires a person to take reasonable measures to determine accurately whether or not a person is under age 18 before selling or supplying liquor. In addition, it specifically places responsibility on the under-18 year old him or herself not to produce, import, or supply liquor to another, as well as prohibiting an under-18 year old from lying about his or her age to obtain alcohol. The penalty for violating these prohibitions is a fine not exceeding R1000 000, or imprisonment for a period not exceeding five years. Section 10 also states that a person must not make a false claim about the age of a minor in order to induce a person to sell or supply liquor or methylated spirits to him or her.

When we see the Kenya's laws on underage drinking, as per Section 24 of Alcoholic Drinks Control Act No. 4 of 2010 of Kenya, no person holding a license to manufacture, store or consume alcoholic drinks shall allow a person under the age of eighteen years to enter or gain access to the area in which the alcoholic drink is manufactured, stored or consumed.

As per section 28, no person shall sell, supply or provide knowingly an alcoholic drink to a person under the age of eighteen years. ${ }^{29}$ A person who contravenes this provision commits an offence and shall be liable to a fine not exceeding one hundred and fifty thousand Kenyan shillings, or to imprisonment for a term not exceeding one year, or to both. ${ }^{30}$ However, it shall be a defense to an offence under this section if it is established that the accused person attempted to verify that the young person was at least eighteen years of age by asking for and being shown any of the documents for the purpose of verifying the age of the young person and believed, on reasonable grounds, that the

\footnotetext{
28 The Secretary of State for the Home Department (2012), The Government's Alcohol Strategy, Printed in the United Kingdom by The Stationery Office Limited on behalf of the Controller of Her Majesty's Stationery Office, pp.6-7.

${ }^{29}$ Section 28 (1) of Alcoholic Drinks Control Act No. 4 of 2010 of Kenya 30 Section 28 (2) of Alcoholic Drinks Control Act No. 4 of 2010 of Kenya
} 
documentation was authentic. ${ }^{31}$ No person shall manufacture or sell objects including sweets, snacks and toys that resemble or imitate alcoholic drinks. ${ }^{32}$ No person shall promote an alcoholic drink at any event or activity associated with persons under the age of 18 years using such things or materials that are associated with minors. According to Kenya Gazette Supplement No. 151 (Senate Bills No.10), which is a Bill for an Act of Parliament to amend the Alcoholic Drinks Control Act, 2010, section 33, a person shall not promote an alcoholic drink or brand related element by including anything in the promotion which might appeal to persons under the age of eighteen years by implying that the consumption of an alcoholic drink is fashionable or the accepted course of behavior. The bill also requires a mandatory warning message to be displayed on every package containing an alcoholic drink, sign or advertisement, i.e., not for sale to persons under the age of 18 years.

American laws on underage liquor consumption differ from state to state, but there are some notable trends. Many states have enacted "zero tolerance" laws in an effort to reduce underage drinking and driving. ${ }^{33}$ In effect, zero tolerance laws ensure that any person under 21 (the legal drinking age in the United States) who is found with a measurable level of alcohol in his bloodstream while driving, or who refuses testing upon a police officer's request, will be penalized, even ifthe driver is not impaired in any way. ${ }^{34}$ One common penalty is the automatic revocation of the youth's driver's license. ${ }^{35}$ Many states have also enacted "social host" liability laws which hold social hosts (including non-commercial vendors) who provide alcohol to another person liable for death or injury that the intoxicated person inflicts on another. ${ }^{36}$ When it comes to minors, some courts have also held that social hosts could be held liable for injuries or death suffered by an intoxicated minor guest to whom the host furnished the alcoholic beverages. ${ }^{3}$

In Germany, three different regulations exist that specifically refer to alcohol marketing and advertising. The 'Jugendschutzgesetz' and the 'Jugendmedienschutz-Staatsvertrag', which are both statutory and the non-statutory 'Code of Conduct on Commercial Communication for Alcoholic Beverages'. 38 The elements of the Council Recommendation are reflected in the 'Jugendmedienschutz-Staatsvertrag' in a very general form. ${ }^{39}$ Section 6 (5) says that "advertising for alcoholic

\footnotetext{
${ }^{31}$ Ibid, Section 28 (3)

32 Ibid, Section $28(5)$

${ }^{33}$ U.S. Surgeon General. (2007) Surgeon General's call to action to prevent and reduce underage drinking. Washington, DC: Department of Health and Human Services, Office of the Surgeon General.pp.35

${ }_{34}^{34}$ Ibid

${ }^{35} \mathrm{Ibid}$

${ }^{36}$ National Research Council and Institute of Medicine. (2004) Reducing underage drinking: A collective responsibility. Richard J. Bonnie and Mary Ellen O'Connell, (Ed.). Washington, DC: National Academies Press.

${ }^{37}$ Ibid,

${ }^{38}$ Kate Barth and Dianne Hubbard, 2009, Alcohol and Youths: Suggestions for Law Reform, monograph no.4, Gender Research \& Advocacy Project Legal Assistance Centre Windhoek, Namibia, pp.7

39 Ibid
}

beverages must neither be directed towards children and adolescents nor be designed to appeal especially to children and adolescents nor show them drinking alcoholic beverages." The 'Code of Coduct' is in practice the main regulation of alcohol marketing and advertising in Germany and the way in which the elements of the Council Recommendation are reflected in German regulation in detail. $^{40}$ The text of it is designed by the advertising and alcohol industry. The German Advertising Council, a self-regularory agency of the German Advertising Federation, is responsible for the complaint and sanctioning system. $^{41}$

\section{The Need of Laws to Enforce Legal Age Limits in Ethiopia}

The right laws and regulations can minimize opportunities for young people to use alcohol and maximize the opportunities for effective enforcement and prevention. ${ }^{42}$ Age limits will only function well when the minimum age for purchasing alcohol is efficiently enforced. ${ }^{43}$ Enhanced enforcement in particular seems to have an impact if the threat of suspending or revoking the license to sell alcohol is used in cases of irresponsible selling. By enforcement of legal age limits we mean the whole of supervision, sanctions and communication used to uphold the laws on age limits for selling and serving alcoholic beverages. Many studies in developed countries show that the effect of enforcement on youth alcohol consumption is considered twofold: enforcement influences the direct availability of alcohol to adolescents and it influences the norms, attitudes and beliefs about the product in society. ${ }^{44}$ Alcohol availability and social norms/attitudes are both strong predictors of drinking behavior.

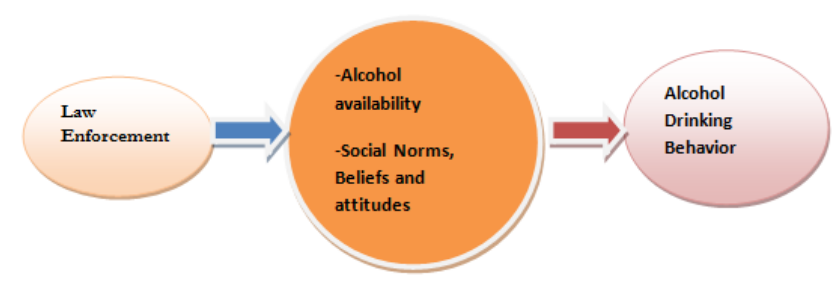
Figure 1. Role of law enforcement in affecting minors' drinking
behavior

Even though some laws governing alcoholic drinks exist

\footnotetext{
${ }^{40}$ Ibid

${ }^{41}$ Ibid

${ }^{42}$ Smith, L.A., \&Foxcroft, D.R. (2009), The effect of alcohol advertising, marketing and portrayal on drinking behaviour in young people: Systematic review of prospective cohort studies. Journal of Public Health, Vol. 9, No.51, pp. $1-11$.

${ }_{43}$ Ibid

${ }^{44}$ European Commission, 2013, Eyes on Ages, a research on alcoholic limit policies in European member states, legislation, enforcement and research [e-book], available at <http//www.europeancommission.com>.

$\underset{\text { pdf,[Accessed } 04 \text { August 2015] pp.12 }}{\text { Ibid }}$
} 
in Ethiopia, their practicability remains questionable. For example, some alcohol outlets state 'no sale' for underage children, but do not demand proof of age identification before selling. Thus, under the circumstances in Ethiopia, children as young as 7 and 10 years of age can purchase alcoholic drinks with no one stop them. There are no restrictions on alcohol advertising. If there were restrictions, minors would not have watched alcohol advertisements on television sitting with their father and mother.Drinks allowed on the media are those with alcoholic contents below $12 \%$ by volume as per the advertising proclamation of Ethiopia. However, larger consumption of these drinks will result in effects similar to that of high-alcohol drinks and should have been regulated. Therefore, the writer of this paper emphasizes on the need for a comprehensive regulation designed to address all issues on underage alcoholic drinks in general. To this effect, separate alcohol policy and regulatory laws must be declared so as to enforce minimum age limits for alcohol consumption in Ethiopia.

\section{Suggestions for Law Reforms on Underage Alcohol Consumption in Ethiopia}

Given the relative ease of access to liquor by under-18 year olds in Ethiopia and the rising prevalence of underage drinking, it is crucial to address the problem of youth alcohol use by introducing new laws and strengthening Ethiopia's laws surrounding underage drinking.This study proposes the following recommendations for immediate law reform to strengthen protections against underage drinking. The proposed reforms attempt to provide an approach which encourages responsibility without excessive criminalization. The writer believes that enforcement and prosecution should continue to focus on the sale and supply of liquor to underage persons ratherthan the consumption of liquor by underage persons.

\subsection{Proposed Law Reforms}

The Ethiopian government should make (introduce) Liquor Control Act of Ethiopia relating to underage drinking like that of South Africa and Kenya. The proposed Liquor Control Act of Ethiopia should prohibit the presence of persons under 18 years old in certain categories of establishments except where in the company of a parent or guardian. The presence of under-18 year olds is not necessarily problematic in places such as restaurants and hotels, but it would seem inadvisable to admit persons who are under the legal age for purchasing alcohol to night clubs unless they are with their parents. Restricting the presence of under-18s in this way would help keep youths out of bars and other places where alcohol consumption is a central activity.

The proposed Liquor Control Act of Ethiopia should also create a legal responsibility for alcohol suppliers and sellers to check identification. The writerwould like tosuggest making the Liquor Act by including a section similar to the South African provision to place affirmative duties on licensed establishments to check Identifications. This would ensure that a person must take active measures to confirm the age of the liquor purchaser or face potential liability. Such a provision would help to encourage stricter enforcement of identification checks in licensed establishments.

The proposed Liquor Control Act of Ethiopia should clarify rules on the use of fraudulent Identifications (IDs) and provide for confiscation of fake IDs. The writerwould like tosuggest that the provisions on identification checks should be bolstered by provisions on the use of fake IDs and the IDs of other persons. He proposes a provision allowing for confiscation of IDs in suspicious circumstances. The proposed Liquor Control Act should also prohibit manufacture of homebrew by under-18 year olds for personal use as well as any possession of liquor by under- 18 year olds, and provide for the immediate confiscation of liquor in such situations. This study proposes making it an offence for under-18s to consume or possess liquor, coupled with a provision empowering the police to confiscate the alcohol if the possessor cannot provide acceptable proof of age. Such an enforcement technique might be the most effective way to prevent immediate harm. At the same time, This study suggest that under-18s who are first offenders in such circumstances should be subject to fines (but not imprisonment) and possibly required to attend education sessions on the risks of alcohol. The goal should be persuasive discouragement rather than a focus on severe criminal sanctions.

Generally, the proposed Liquor Control Act of Ethiopia should include the following concepts.

- The proposed Liquor Control Act of Ethiopia should prohibit anyone, except a parent or legal guardian, from providing alcohol to any person under the age of 18. No person shall sell, give or make alcohol available to a minor. A parent or legal guardian may provide alcohol to their minor child in a private residence as long as the parent is with the minor child. If you illegally provide alcohol to a minor, or provide alcohol to an adult that you know will make it available to a minor, you will receive a criminal citation. Parents or guardians may legally provide alcohol to their minor child or ward and only in a private residence when accompanying their minor child. A parent cannot transfer this responsibility to another adult or provide alcohol in a public place. If anyone allows his/her property and/or home to be used for a party where minors, other than his/her minor child (ren), consume alcohol in his/her presence, he/she may have to forfeit property and may be issued a criminal citation.

- The proposed Liquor Control Act of Ethiopia should state that when minors misrepresent their age, purposely are not truthful about their age to purchase 
alcohol, enter a lounge or evade detection by law enforcement, they are referred to juvenile court or receive a criminal citation, depending on their age. The minor may be fined. If identification is used in misrepresentation, the minor's driving privileges may be suspended for up to one year and/or the minor will have to wait for up to one year to apply for a driver's license.

- The proposed Liquor Control Act of Ethiopia should state that when minors are in possession of alcohol, they are either holding the alcohol, have consumed the alcohol, or attempted to purchase the alcohol, they will be referred to juvenile court or receive a criminal citation. The minor will be fined and/or required to perform community service. Minors/juveniles may be sent to alcohol assessment and treatment. Minors may consume sacramental wine as part of a religious service.

- The proposed Liquor Control Act of Ethiopia should state that when any officer arrests a person for violating a liquor law (e.g.; selling alcohol without a license) the officer may take into possession all alcoholic beverages and other property used in violation of the law. Other properties that can be confiscated include: bars, glasses, chairs, tables, music devices, furniture, and equipment. This property is forfeited to the state of Ethiopia if the person is convicted.

- The proposed Liquor Control Act of Ethiopia should state that any room, house, building, boat, structure or place of any kind where alcohol beverages are sold or given away to minors in violation of the law is a public nuisance. Anyone who maintains or assists in maintaining such a place, or permits it in a place they own, manage or lease, violates the Liquor Control Act.

- The proposed Liquor Control Act of Ethiopia should state that it is illegal for someone exercising control over private real property to allow any person under 18 years old to consume alcohol on the property in his/ her presence. It is also illegal to allow any person under age 18 to remain on the property if they have consumed alcohol. Private real property may include a hotel room, camp site, or any rented/leased location. The only exception is for his/ her own minor child (ren). If he/ she control an area where minors consume alcohol, he/ she will receive a criminal citation.

- The proposed Liquor Act of Ethiopia should state that as a licensee, permittee or social host, you may be liable for injuries caused by a minor who obtained alcohol from you when you did not properly check for identification. Minors who misrepresent their age and cause a licensee to be fined or have their liquor license suspended or revoked can be held liable for damages sustained by the licensee.

\subsection{Model Provisions for the Proposed Liquor Control Act of Ethiopia}

Finally, this study recommends the following provisions modelled primarily on the South African law with additional features from Kenyan, American and German liquor control laws.

(1) (a) It shall be an offence for any person to sell or supply liquor to a person under the age of 18 years.

(b) A person must take reasonable measures to determine accurately whether or not a person is over the age of 18 , before selling or supplying liquor to that person, and failure to do so will bar a person who has violated subsection (a) from asserting the defense that he or she was mistaken about the age of a person in respect of that subsection.

(2) (a) notwithstanding subsection (1), it is permissible for a person who is over age 15 and under age 18 to consume a moderate quantity of liquor, in light of his or her age, in the presence and under the responsible supervision of the parent or guardian of such person.

(b) Notwithstanding subsection (1), it is permissible for a person who is under age 18 to consume a small quantity of liquor as part of a religious sacrament in the presence of the person responsible for administering the religious sacrament.

(3) (a) It is an offence for a licensee, or manager or employee of such licensee to allow any person who is under the age of 18 to be present in a licensed shebeen, night club or dance hall unless accompanied by his or her parent or guardian.

(b) A licensee, or manager or employee of such licensee, must take reasonable measures to determine accurately:

(i) the age of the person in question; or

(ii) whether an adult accompanying a person under the age of 18 is in fact the parent or guardian of the under-18 year old before admitting such person to a licensed shebeen, night club or dance hall, and failure to do so will bar a person who has violated subsection (a) from asserting the defense that he or she was mistaken about the age or identity of any person in respect of that subsection.

(c) Where a person under the age of 18 is present in a licensed shebeen, night club or dance hall with his or her parent or guardian, it shall be an offence for a licensee, or manager or employee of such licensee to sell or otherwise provide before admitting such person to a licensed shebeen, night club or dance hall, and failure to do so will bar a person who has violated subsection (a) from asserting the defense that he or she was mistaken about the age or identity of any person in respect of that subsection.

(d) Where a person under the age of 18 is present in a licensed shebeen, night club or dance hall with his or 
her parent or guardian, it shall be an offence for a licensee, or manager or employee of such licensee to sell or otherwise provide liquor to such parent or guardian if that parent or guardian appears to a reasonable person to be intoxicated or if the vendor is reasonably concerned about the health, safety or welfare of the under-18 year old.

(4) (a) It shall be an offence for a person to falsely represent himself or herself, or any other person, to have attained the age of 18 years for the purpose of obtaining liquor in violation of this law, or for the purpose of entering into premises where the presence of persons under age 18 is restricted.

(b) It shall be an offence for a person to -

(i) make a false document;

(ii) sell or supply a false document to another person; or

(iii) willfully deface or alter any document; with knowledge or a reasonable suspicion that the document may be used as false evidence of age for the purposes of this Act.

(c) It shall be an offence for a person to give a document that is evidence of age of the person mentioned in the document to someone else, if the person giving the document knows or has a reasonable suspicion that the document may be used as evidence of the age of someone other than the person actually referred to in the document, for the purposes of this Act.

(d) A licensee, or manager or employee of such licensee who has a reasonable suspicion that a document is being presented as false evidence of age in violation of this subsection must seize and confiscate the document and turn it over to a member of the Ethiopian Police Force or a municipal police force within 48 hours for purposes of police investigation

(5) (a) It shall be an offence for a person under the age of 18 to -

(i) consume liquor other than as provided in subsection (2);

(ii) produce liquor;

(iii) possess liquor;

(iv) import liquor; or

(v) supply liquor to any other person.

(b) A member of the Ethiopian Police Force or a municipal police force who finds liquor, whether in an opened or unopened container, in the possession of a person who cannot provide reasonable evidence that he or she has attained the age of 18 years may immediately confiscate that liquor without a warrant.

(6) The provisions of the Criminal Procedure Code of Ethiopia on seizure and forfeiture shall apply to any documents or liquor seized in terms of this section.

(7) (a) A first offender under the age of 18 who is guilty of any offence under this section, and a first offender of any age who is guilty of an offence under subsection (4), shall be subject to a fine not exceeding 300 Ethiopian Birr, and in addition to such fine, may be required to attend educational sessions on the dangers of underage drinking upon conviction or admission of guilt.

(b) The penalties shall otherwise apply to the offences set forth in this section, provided that an offender may be required to attend educational sessions on the dangers of underage drinking in addition to the penalties provided therein. 